\title{
Who Does What: Unprofessional Personnel Policies
}

Mr. Williams, assistant to the librarian at Harvard College Library, has made use of American Library Association statistics and of other data gathered independently, to deal with certain aspects of the segregation of professional and clerical work in college and university libraries.

IBRARIANS have not formed the habit of $\mathrm{L}_{\text {striking for higher pay, but few of }}$ them, especially when they write on personnel, resist the temptation to hint that better salaries would be desirable. Rather than repeat old arguments or devise new ones on that subject, it may be useful, in an article that is to be read by librarians, to examine a situation that may help to explain the relative failure of the traditional propaganda for wage increases. This paper, therefore, will be concerned with the correlation, in college and university libraries, between the number of employees of various grades and the quantity of work of corresponding grades that is done. Two axioms are involved at the outset: first, that some of the employees of a library are professional, while the remainder are not; second, that some of the work in a library can be done adequately only by professional workers, while the balance need not be done by them.

The professional employees mentioned in the first axiom are defined, in the A.L.A. statistical report forms, as persons "performing work of a professional grade which requires training and skill in the theoretical or scientific parts of library work as distinct from its merely mechanical parts. ....A professional position ... requires the following educational background: (a) At least a bachelor's degree which includes one year of professional library education in the four years which lead to the bachelor's degree; or (b) An informal education considered by the librarian as the real equivalent of four years of college work, plus five years' experience in a library of recognized professional standing."

There is some room for variation in interpretation of the last section, and perhaps not all statistics reported by all libraries are completely accurate, but, subject to these relatively minor reservations, Table $A$, at the end of the present paper, shows how the personnel has been divided in fifty college and university libraries during recent years. This table, it should be added, includes all institutions for which the necessary statistics have been published for three or more of the past eleven years; the figures printed prior to 1932-33 cannot be used in this connection.

\section{Percentage of Total Work}

Much less information is available about the other percentage in question-the percentage of the total work that is of professional grade. An official definition of such work is lacking, though it is reported that an A.L.A. committee is at present listing and classifying, as professional or nonprofessional, the tasks performed in college and university libraries. It would hardly seem possible to make any position purely 
professional; nothing more clearly calls for library training than reference work, yet nearly every reference librarian spends an appreciable portion of his time on questions that could be answered equally well by anyone who knows his way around the library building. Also, unless a "task" comprises only the most minute possible unit of work, a task that is professional in one library might, with a different organization of the work, become several tasks or portions of several tasks, only one of which might be professional. ${ }^{1}$ While it may never be possible to sort and classify the work done in libraries as neatly as the personnel, it is nonetheless surprising that there appears to be no published record of any effort to arrive at even an approximation of the percentage of professional and nonprofessional work, either for college and university libraries in general or for any individual institution.

\section{Is Correlation of Importance?}

Before examining what can be discovered with regard to the correlation between personnel and work, however, it would seem prudent to decide whether or not such a correlation is of sufficient importance to warrant discussion. It would matter, obviously, if evidence were to be uncovered that, in many libraries, a higher percentage of the work than of the staff is of professional grade. If this sort of noncorrelation is not to be found, however, a pertinent enquiry is: Would it matter if the percentage of professional grade personnel should be discovered, in many cases, to be much higher than the percentage of professional grade work?

If noncorrelation in this direction is a danger, relatively little attention has been given to it in library literature, and surely

1 Probably the greatest opportunities for reorganiza. tion of this sort are in cataloging. A description of developments in this field at Harvard (for which the present author has neither the space nor the qualificapresent author has neither the
tions) ought to be published. its results could not be so clearly or immediately damaging as lack of correlation of the opposite sort. If its reference librarians, bibliographers, and catalogers are inadequate in quality or quantity, a library will give poor service immediately and will rapidly deteriorate in every respect; but, if all of the pages in a library were doctors of philosophy from the Graduate Library School, the service would not suffer and, indeed, the faculty might find it convenient to have these experts scattered through the stacks.

Still, there are at least two evident reasons for suspicion that noncorrelation of the latter sort would be undesirable. Economy is one consideration: the professional librarian, by definition, has training that the nonprofessional does not have, and a library must be wasting money if it is paying for skills that it does not use. The second consideration involves professional standards. It would seem difficult for librarianship to attract and hold desirable recruits if it were not making use of their abilities, and, likewise, extensive use of professionals for clerical work might not make it easier to improve salary schedules.

But the argument on the basis of economy, at least, cannot be accepted without question. Under war circumstances it often is easier to secure professional than clerical workers. And one might argue that there is, or will be when conditions return to normal, a surplus of trained librarians; that they do clerical work at least as well and as cheaply as nonlibrarians; that many of them are not good for much else anyway; and that they are easier to use because they do not require so much supervision or such careful organization and division of labor. It would be difficult, if not impossible, to demonstrate that an administrator, if this is the situation, is not furthering the best interests of his library when he uses surplus profes- 
sionals for any sort of work that needs, to be done.

Such a conclusion may be reasonable and even inevitable, but it can hardly be accepted without protest by one who is interested in the welfare of the profession. For one thing, it is doubtful that there is or will be, in the near future, a real surplus of professional skills. Few libraries are now doing all the reference work they would like to do or giving as much attention as could profitably be given to building up the collection or improving the catalog. Much more professional work could be undertaken if trained librarians were relieved of clerical duties.

\section{Vicious Circle}

Much more important is the realization that consenting to this situation means, in effect, accepting a vicious circle-or descending spiral-of personnel surplus, resulting in clerical grade work and low wages, both of which, in turn, mean inferior recruits. The latter, of course, help to insure continued low-grade work and low wages. One cannot reasonably hope that efforts at recruiting will improve the quality of library personnel as long as this condition prevails. High wages might reconcile some talented persons to work largely clerical, while really important and stimulating duties might attract some firstrate people in spite of low wages; but the fatal combination perhaps leaves librarianship only the appeal of a rather spurious gentility that may fail to attract much vigor or intelligence to the profession.

A comparison with medicine or teaching might make the point more clear: A surplus of personnel in those fields will force some doctors to struggle to make a living from a poor practice and some teachers to accept a few hundred dollars a year in country schools or fifth-rate colleges; but the doctor or teacher, however low his earnings, still has patients or pupils and can still make good use of the skills or talents he possesses for healing or teaching. It could hardly be maintained that a librarian reduced to filing or typing has a comparable opportunity to utilize his native abilities and his library training; efforts to improve his speed or accuracy will not greatly improve his mind or far extend his professional knowledge and competence. And it could be argued that, if this situation is accepted, a library school must be either very optimistic or not entirely conscientious when it attempts to recruit firstrate students.

The A.L.A. statistics, as noted, have made it possible to prepare a table showing the distribution of personnel in fifty college and university libraries. The percentage of professional staff members varies widely. In one group of libraries-which includes Harvard, California, Texas, Pennsylvania, Iowa State College, Oberlin, and Vassar-professional workers make up only from 30 to 40 per cent of the total staff; at the other extreme, with from 56 to 96 per cent professional, are Illinois, Michigan, U.C.L.A., Louisiana, Syracuse, Wellesley, Denver, Mount Holyoke, Smith, Arizona, Colorado State, Southern Methodist, and North Dakota. The average is very near 50 per cent, since exactly half of the libraries are above and half below that figure. There is clearly some tendency for the smaller libraries to have higher percentages of professionals.

\section{Work Differences}

The first question that naturally arises is whether or not the differences in percentages of professional staff members result, at least in large part, from corresponding differences in the work done in the various libraries. If one found, for example, that Illinois does twice as much professional and half as much clerical work 
as Harvard, it would be natural for it to have twice the percentage of professional personnel, and the difference in percentages would not imply any difference in the correlation between work and personnel.

If only a few librarians were to be imposed upon by a request for opinions on this and other questions arising in connection with the study, it seemed that the most light might be thrown on the subject by directing inquiries to administrators of a few of the libraries with the highest and lowest percentages of professional personnel. Replies came from directors or librarians of four of the "high percentage" and five of the "low percentage" librariesto all of whom the author is grateful.

Each administrator was asked if he believed that the difference between the percentage of professionals on his staff and the percentage in libraries at the other percentage extreme resulted from differences in the work done or, at least in large part, from genuine differences in the extent to which trained librarians are used for clerical work. Three of the nine who replied (including two from "high percentage" libraries) indicated that, as far as they could see, the differences in personnel bore no relation to differences in the work done. None of the replies asserted that the differences were entirely accounted for in this way, but several factors were suggested as having some bearing on the problem.

\section{Many Professional Members}

Several replies pointed out that the library of an institution where classes are small and many undergraduates are engaged in independent study calls for a relatively large percentage of professional members on the staff: "The smaller library is often a teaching instrument even more than a collection of books, and this teaching function calls for professional people."
Undoubtedly there is merit in this contention, but it is surprising to discover that, in the four women's colleges to which this theory presumably might be particularly applicable, the percentage of professional workers runs from 38.I at Vassar, through 58.2 at Wellesley, 72.3 at Mount Holyoke, and 83.9 at Smith. Smaller classes and independent study might help to account for the discrepancy between one of these colleges and some other institutions on the table, but the remarkable differences among the colleges themselves remain unexplained.

It was suggested that there might be some relation between professional staff percentages and the volume of annual accessions or of circulation, but careful examination of the statistics has failed to reveal any significant correlation with either item. The likeness that has been noted between the percentage and the size of the library might be expected, regardless of any difference in the percentage of work, since it would obviously be more difficult to divide professional from nonprofessional tasks in a library where there are very few employees per department.

A suggestion that at first glance seemed very promising, was that institutions with numerous special and departmental libraries would be expected to have larger percentages of professional workers, because a small separate collection may require professional supervision and yet not involve enough work to warrant a clerical staff. $^{2}$ Fortunately, it was possible to obtain a breakdown by departments of the staff at Harvard, Texas, and Illinois, as shown in Table B. This indicates that, at least in the case of these three institutions,

2 On the other hand, one may cite Mr. Coney's "policy of 'stretching', branch librarians over more than one branch library" (College and Research Libraries $4 \mathrm{i}^{2} 29$, June $\mathrm{r} 943$ ), and point out that there is
usually plenty of professional work that could be done usually plenty of professional work that could be done
in a branch library if the librarian were not loaded down with clerical duties. 
the percentage of professionals in departmental libraries is close to the percentage of professionals for the whole library and, consequently, has no appreciable affect on the latter percentage. The same table shows that the difference between the percentage at Harvard and Texas on the one hand and Illinois on the other, runs all through the staff, department by department-which may be taken as another indication that policy plays a greater part than varying proportions of professional work in causing the difference.

\section{Library School on Campus}

The one obvious correlation revealed by the table is between a high percentage of professionals and the existence of a library school under the same administrator as the library. Denver, Illinois, Louisiana, Michigan, ${ }^{3}$ and Syracuse are all among the "highs." But the presence of a library school affects the availability of trained personnel and may influence personnel policy; no one asserts that it has a significant affect on the work load of the library.

Finally, all four administrators of "high percentage" libraries, whether or not they believed their high percentages to be desirable, stated that their professional staff members were doing a considerable amount of clerical work. It seems fair to conclude that a preponderence of evidence favors the view that work differences do not explain very much of the variations in percentage of professional employees shown by the table, and that these percentages do reflect, to a large degree, differences in the extent to which professional members are being used for clerical work.

One administrator argues that a high percentage of professional workers makes possible higher standards of service and implies higher ideals of librarianship. Con-

\footnotetext{
3 At Michigan, the school is no longer under the director at the library, although it was until recently.
}

sequently, it seems necessary to examine what evidence there is as to whether the most desirable situation, for the average library, appears to lie in the upper region of nearly 60 per cent or more professional people; toward the middle, around 50 per cent; or, perhaps, in the low area between 30 and 40 . With this in mind, each librarian consulted was asked whether or not he was reasonably well satisfied with the distribution of his own staff as of I940-4I. Of the four "high percentage" libraries, one expects a rise in the percentage (due to a surplus of librarians who can be used for clerical work), and the other three hope for a moderate decreasetwo of them to 50 per cent or a little more. This suggests something of a trend toward the average;" but replies from the "low percentage" libraries do not bear this out, for one of the five wishes to remain about where it is, three desire to reduce their percentages still more, and only one would like an increased percentage of professional workers. If the average- 50 per cent-is desirable, it is hard to see why one library is satisfied at present and four wish to go still farther from the mean. If the "high percentage" group is the best off and if it really does improve the service and raise professional standards to use trained librarians for much clerical work, it is surprising, at least, that four out of the five "low percentage" administrators want to stay where they are or go still lower.

\section{Texas Time Study}

Obviously, these administrators do not believe that they are forcing their nonprofessional staff members to do work of professional grade. The only objective evidence on this point, however, is provided by the results of a time study made

4 Indeed, the decrease desired at Wellesley will bring that library well below the average of the four women's colleges. 
at Texas in 1939 at the request of the subcommittee preparing the A.L.A. classification and pay plans. ${ }^{5}$ Over a two-week period, each staff member indicated exactly how much time he spent on each of 127 listed tasks. A number of these tasks, unfortunately, cannot be definitely classified as professional or nonprofessional; but examination of the time sheets does seem to justify the conclusion that the professional staff at Texas, comprising $4 \mathrm{I}$ per cent of the whole staff at that time, was spending more than a quarter of its time on clerical tasks. This appears to justify the subsequent reduction of the percentage there to 30 or slightly less.

Unless this is in error, and unless administrators at Harvard, Texas, Iowa State College, and other "low percentage" libraries are mistaken, there are enough trained librarians in these libraries to do the professional work; consequently, the percentage of professional grade work in these libraries must be 30 or less. It follows that, if the proportion of professional grade work does not vary greatly from library to library, at least half the time of the whole professional staff at some of the other libraries listed in the table must be devoted to clerical tasks.

This does not imply that the "high percentage" libraries are in an undesirable condition from the standpoint of the public they serves it has been pointed out that the public might not suffer if all pages were doctors of philosophy. It does not imply, as long as librarians are as cheap as clerical workers, that the "high percentage" libraries are being administered uneconomically. But there is good reason to fear, it

${ }^{5}$ Cf., Classification and Pay Plans for Libraries in Institutions of Higher Education, Vol. III, Universities. Chicago, A.L.A., I943, p. ix. Unfortunately, the A.L.A. no longer has a complete set of time sheets for any of the participating libraries, and Texas, as far as the author has been able to learn, is the only library that has preserved a duplicate set of its own sheets. has been seen, that the situation is undesirable from the standpoint of the library profession-clerical work for trained librarians is a part of the vicious circle that entails low salaries and inferior recruits. 1

\section{Subprofessionals}

I It might be reasonable to expect that an administrator who wished to keep the percentage of professional members on his staff as low as possible would find it desirable to employ some nonprofessional persons of a higher grade than would be needed in an institution where librarians were doing much of the clerical work. This consideration suggests that attention ought to be drawn to the question of "subprofessionals." The A.L.A. definition is not very satisfactory and, perhaps, is often interpreted rather freely; in the classification and pay plans mentioned above, the grade is omitted entirely on the ground that it is little used. It should be added that the term "subprofessional" is unsatisfactory. If "librarian" is to be included in the name of all professional positions, as recommended, then "assistant" might be proposed in place of "subprofessional." In any case, the group in question would fall between the pages, typists, filers, etc., and the professional workers, and it might be expected, normally, to be composed of college graduates with some library experience. Mr. Coney suggests that the distinguishing feature should be that this group has responsibility for making decisions but in a narrower field than professional members have.

Perhaps the best indication that recognition of some such intermediate grade of service is of use, if one wishes to hold professional positions to a minimum, is the fact that all five of the administrators of "low percentage" libraries thought the subprofessional grade desirable, while all three 
of the "high percentage" librarians who replied to the question were opposed to such a grade.

But wider acceptance of subprofessional workers, if desirable, is not a means of solving the basic problem so much as an expedient that would naturally accompany progress toward a solution. If a shortage of librarians could be created there would be reason to hope that the situation-low wages, clerical work, and inferior recruits -would change for the better. True, there is supposed to be a shortage at present and it does not seem to have reduced the percentage of professional people materially, but, as shown by one of the replies that was quoted, an even greater shortage of clerical labor, at least in some localities, more than counterbalances the shortage of librarians. If clerical labor were plentiful, while librarians were not, there can be little doubt that considerations of economy would force changes of personnel policy. In any case, there is little prospect of creating a shortage.

\section{Suggested Procedure}

No single administrator, of course, could change the situation throughout the profession, but it may be worth while to suggest a procedure that would, if followed by enough administrators, give promise of improving conditions. The suggestion, in brief, is that the administrator act as if he were going to face a shortage. If librarians were going to be strictly rationed, or to cost $\$ 20,000$ each, the director presumably would go through his staff, department by department and person by person, and try to determine, by job analyses, time records, interviews, or other means, what percentage of the time of each professional employee was taken up with clerical work.।

He might find, for example, that a department had twenty employees, of whom twelve were professional, each devoting a certain fraction of his time to nonprofessional tasks. If these fractions added up to three or a little more, it would mean that the department could operate with three fewer professionals and three more clerical employees. Then, when a professional member left the staff, his professional duties would be divided among the remaining professional ones, and a new clerical position would be created to take over the nonprofessional duties left unassigned by these shifts. After three librarians had left, all of the professional duties would be concentrated in nine professional positions, and these positions would be nearly roo per cent professional in content. If funds were available and the work warranted it, the readjustment might be made more quickly by adding three clerical positions at once, thus releasing the equivalent of three full-time librarians for additional professional work, which, in most departments, could be used to advantage. In any case, the professional positions in the library would soon be almost purely professional.

If a shortage then really developed, the library would be ready to make the maximum use of its personnel resources. As long, however, as there was a surplus of trained librarians, there is no reason why unemployed professionals should not be hired for clerical positions-as long as it was not forgotten that the positions were clerical.

\section{Results of Surplus}

If the anticipated postwar surplus should materialize, trained librarians would then still be doing clerical work, and it might seem that little, if anything, had been gained by the careful segregation and classification of positions. The gain that is sought, however, would arise from the 
fact that no one would then be deceived. The administrator would know that he was hiring trained librarians because they were available, not because he had to have them. The library school would know whether or not a real shortage existed; it would know just how many of its graduates were being placed in professional work and how many were able to get only clerical jobs in libraries. The individual, if he had to accept a clerical position, would know that he had not been "placed" and would not stay, unless some strong personal consideration warranted it, when he had an opportunity to secure professional work. Inferior products of the library schools would be weeded out in the process; indeed, general adoption of such a system might be an effective means of inducing the schools to do as much as possible of the weeding out themselves and ultimately reduce the surplus of librarians.

It will be much easier simply to continue traditional agitation for better salaries. The conclusion proposed here is unsatisfactory, too, because it amounts to little more than expression of the hope that library administrators will go to considerable trouble to do something that will not benefit their libraries very directly and certainly not very quickly. To be sure, the low percentages of professional employees reported by some libraries suggest that some administrators may already have done much of what is proposed, but other percentages hint that many more have not succeeded in doing it. Thoughtful librarians surely have always been aware of the basic problem that has been pointed out, and any facts that may have been presented here for the first time can scarcely do more than support conclusions that their own observations have already suggested. Only an optimist would expect it to be less difficult to improve the situation in the future than it has been in the past.

TABLE A

Percentage of Total Staff in Each Grade of Personnel

Average for all years reported

\begin{tabular}{|c|c|c|c|c|c|c|c|}
\hline & & & & & & & \\
\hline Harvard & 6 & 164.5 & 30.6 & 19.3 & 2.8 & $4 \mathrm{r} \cdot 4$ & 5.9 \\
\hline Yale & 7 & I 46.8 & 45.8 & 15.3 & I. 6 & 33.4 & 3.9 \\
\hline Illinois & II & I 46.4 & $57 \cdot 3$ & 1.7 & o & 8.8 & 32.2 \\
\hline Michigan & 9 & 138 & 61.8 & 10.5 & o & 12 & 15.7 \\
\hline California & 9 & 124.8 & 39.5 & 1.7 & .7 & 12.4 & 45.7 \\
\hline Chicago & 8 & 122 & $49 \cdot 3$ & 18.2 & .6 & $7 \cdot 5$ & $24 \cdot 4$ \\
\hline Iowa & II & $9 \mathrm{I}$ & 44.7 & 5.9 & 1.5 & $4 \cdot 4$ & 43.5 \\
\hline Texas $^{1}$ & 8 & 77.6 & 39.4 & 13 & I.I & 8.8 & 37.7 \\
\hline Duke & 6 & 69.8 & 44.2 & 21.4 & .2 & 8.2 & 26 \\
\hline Princeton & 5 & 69 & $45 \cdot 3$ & 6.6 & 4 & $4 \mathrm{I} \cdot 7$ & 2.4 \\
\hline $\begin{array}{l}\text { Washington } \\
\text { (Seattle) }\end{array}$ & 7 & 67.7 & $47 \cdot 3$ & o & 1.5 & 50.4 & .8 \\
\hline C. & 4 & 56.8 & 58. & 0 & 0 & 17.2 & 24 \\
\hline nns & 10 & 56 & 38.3 & 38.9 & $x .4$ & 17 & 4.4 \\
\hline
\end{tabular}

I940-4I

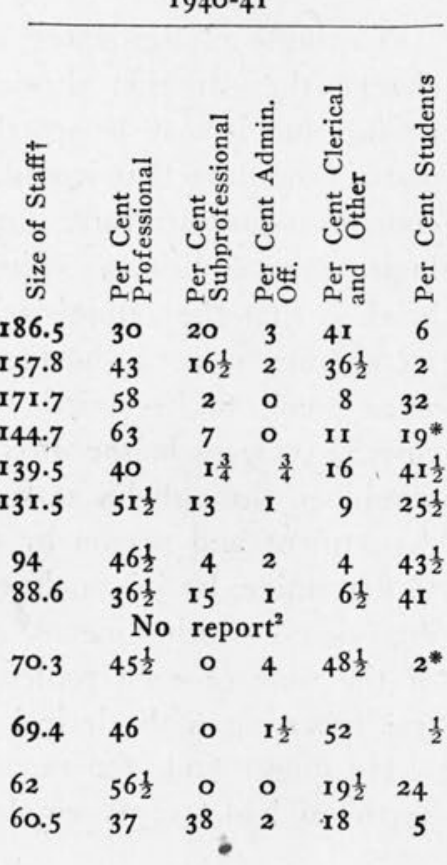


TABLE A

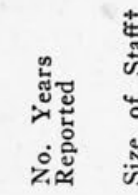

苞
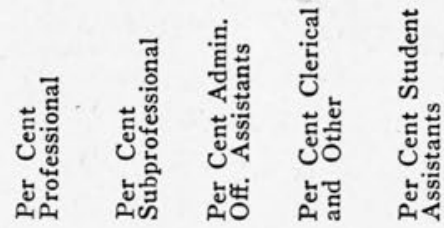

$8 \quad 55.9$

$5 \quad 55.9$

I0 54.1

II 50.8

3
11

\section{3}

45.1

45

43.I

43.1

42.5

4r. 6

38.4

37.7

37.5

37.4

37

35.5

35.3

34.9

28

$$
28
$$

27.1

26.9

24

22

2 I.

59.4

50.2

42.4

43.4

$\begin{array}{ll}.5 & .9\end{array}$

6.1 2

$17.2 \quad 1.2$

4.9 I

44.4

52.1

40.4

38.7

42.6

38.8

48.9

51.4

50.5

30.9

50.8

85.5

53.7

49.1

55.5

9 I

$18.7 \quad \mathrm{I}$

I 4.9

$\begin{array}{ll}15.3 & 2.8\end{array}$

2.I 1.8

I5 2.6

$\begin{array}{ll}6.4 & 1.8\end{array}$

7.5

9.5

20.6

II.I 2 .7

I.9 1.7

4.1 2.9

I 7.9

7.6

$\begin{array}{ll}58.2 & 10.8\end{array}$

$38.1 \quad 13.2$

$46.3 \quad 5.9$

44.6

56.7

17 0

.70
Louisiana

Joint U. Ls.

Dartmouth

Rochester

Brown

North Carolina

Pittsburgh

Cincinnati

Kansas

Iowa State

Penn. State

Nebraska

Oregon

Oberlin

Temple

Syracuse

Oregon State

Missouri

Georgia

Wellesley

Oklahoma

Wayne

Arkansas

Michigan State
Vassar

Washington

(St. Louis)

Baylor

Denver

Mt. Holyoke

Smith

Arizona

Colorado State

Southern Methodist 5

Wyoming

Colgate

South Dakota

North Dakota

$\begin{array}{rrlllcl}7 & 19.8 & 48.1 & 17 & 4.3 & 17.2 & 13.4 \\ 8 & 19.5 & 20.9 & 1.4 & 0 & 0 & 77.7 \\ 3 & 17.2 & 57.2 & 0 & 5.2 & 0 & 37.6 \\ 4 & 16.3 & 72.3 & 0 & 6 & 11.2 & 10.5 \\ 4 & 15.8 & 83.9 & 0 & 1.7 & 0 & 14.4 \\ 5 & 12.7 & 67.9 & 1.4 & 0 & 1.3 & 29.4 \\ 8 & 12.3 & 65.2 & 7 & 2.6 & 11.3 & 13.9 \\ 5 & 11.8 & 75 & 8.2 & 0 & 2 & 14.8 \\ 7 & 10.5 & 54.9 & 2.2 & 6.6 & 3.9 & 32.4 \\ 6 & 8.2 & 53.3 & 18 & 0 & 4.2 & 24.5 \\ 5 & 8.2 & 52.9 & 3.2 & 0 & 3.2 & 40.7 \\ \text { I1 } & 6.3 & 67.7 & 2.9 & 0 & .6 & 28.8\end{array}$

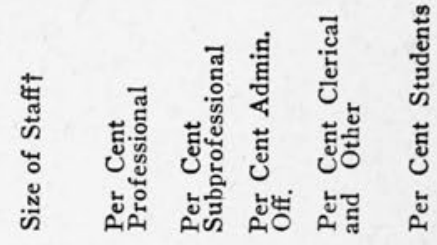

$\begin{array}{llllll}74.3 & 58 & 0 & \text { I } & \text { I } & 40\end{array}$

$\begin{array}{llllll}58 & 48 & 3 \frac{1}{2} & 2 & 2 \frac{1}{2} & 44\end{array}$

$\begin{array}{llllll}55 & 47 & 17 & 2 & 24 & \text { 10 }\end{array}$

$\begin{array}{llllll}53.7 & 39 & 9 & 2 & 33 \frac{1}{2} & 16 \frac{1}{2}\end{array}$

$\begin{array}{llllll}55.3 & 45 & 9 & 2 & 38 \frac{1}{2} & 5 \frac{1}{2}\end{array}$

$\begin{array}{llllll}52.3 & 54 \frac{1}{2} & 29 \frac{1}{2} & 2 & 0 & 14\end{array}$

No report ${ }^{3}$

$\begin{array}{lllllll}47.4 & 44 \frac{1}{2} & 10 \frac{1}{2} & 2 & 23 & 20\end{array}$

$\begin{array}{llllll}40.7 & 42 & 2 \frac{1}{2} & 2 \frac{1}{2} & 2 \frac{1}{2} & 50 \frac{1}{2}\end{array}$

$\begin{array}{llllll}48.5 & 39 & 18 \frac{1}{2} & 2 & 16 \frac{1}{2} & 24^{*}\end{array}$

$\begin{array}{llllll}45.2 & 55 \frac{1}{2} & \circ & 2 & 2 & 40 \frac{1}{2}\end{array}$

No report ${ }^{4}$

$\begin{array}{llllll}45.2 & 5^{2 \frac{1}{2}} & 8 & 2 & 2 & 35 \frac{1}{2}\end{array}$

$\begin{array}{llllll}39.7 & 33 \frac{1}{2} & 17 & 2 \frac{1}{2} & 41 & 6^{*}\end{array}$

$\begin{array}{llllll}43.2 & 42 & 13 & 2 & 18 & 25\end{array}$

No report $^{5}$

$\begin{array}{llllll}42.1 & 55 & 0 & 3 & 0 & 42\end{array}$

$\begin{array}{llllll}48.8 & 49 & 0 & 2 & \text { 10 } & 39\end{array}$

$37.7 \quad 55 \frac{1}{2} \quad 6 \frac{1}{2} \quad 3 \quad 24 \quad$ II *

$\begin{array}{llllll}30.1 & 56 \frac{1}{2} & \text { 10 } & 3 \frac{1}{2} & 23 & 7\end{array}$

No report ${ }^{6}$

$\begin{array}{llllll}20.2 & 59 & \text { 10 } & 5 & 0 & 26\end{array}$

24.1 $50 \quad 12 \frac{1}{2} \quad 0 \quad 8 \quad 29 \frac{1}{2}$

$27 \quad 55 \frac{1}{2} \quad 0 \quad$ O $\quad$ II $33 \frac{1}{2}$

$\begin{array}{llllll}33 & 33 & 2 & 0 & 32 & 33\end{array}$

t All employees, including, student assistants, reduced to full-time equivalents.

* Total lours worked during year by students not reported; figure based on estimate of hours as indicated by rate paid and total expenditure for student help.

I. $1944: 281 / 2$ per cent professional.

2. r $942-43$ : 35 per cent professional.

3. $1942-43: 47$ per cent professional.

4. $1942-43$ : 54 per cent professional.

5. 1942-43: 95 per cent professional (according to A.L.A. statistics); $1943 \cdot 44$ : 58.2 per cent (reported by director).

6. $1942-43: 33^{1 / 2}$ per cent professional.

7. No report since $1938-39$.

8. 1938-39: 8 I per cent professional; no later report.

9. $1942-43: 59 \frac{1}{2}$ per cent professional. 
TABLE B

Distribution of Staffs by Departments

\begin{tabular}{|c|c|c|c|c|c|c|c|c|c|}
\hline \multirow[b]{3}{*}{ Catalog } & \multicolumn{3}{|c|}{$\begin{array}{c}\text { Total } \\
\text { Employees }\end{array}$} & \multicolumn{3}{|c|}{$\begin{array}{c}\text { Numbers of Professional } \\
\text { Employees }\end{array}$} & \multicolumn{3}{|c|}{$\begin{array}{l}\text { Per Cent Professional o } \\
\text { Whole Staff of Each } \\
\text { Department }\end{array}$} \\
\hline & 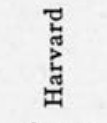 & 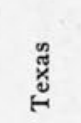 & 总 & 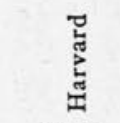 & 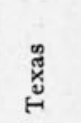 & 总 & 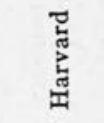 & 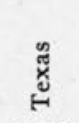 & 号 \\
\hline & 63.19 & 20.3 & 47.75 & 26.44 & 6 & 30 & 42 & 29.6 & 62.8 \\
\hline Acquisition & 8.6 & 7.2 & 28.25 & 4.2 & 3 & 19 & 49 & 41.7 & $67 \cdot 3$ \\
\hline Administration & II.55 & 7.2 & 10.25 & 2 & 2.7 & 3 & $17 \cdot 3$ & $37 \cdot 5$ & 41.4 \\
\hline Binding* & 6.7 & 5.1 & II & o & 0 & 4 & o & 0 & 36.4 \\
\hline Loan & 35.94 & 20.6 & 39.75 & 3.14 & 3 & 16 & 8.8 & 14.6 & 40.3 \\
\hline Reference & 3.5 & 2.8 & 7.25 & 2.5 & 2.5 & 7 & 71.5 & 89.3 & 96.4 \\
\hline Special Colls. & 17.2 & 13 & o & 6.8 & 4 & o & 39.5 & 30.8 & 0 \\
\hline Departmental Libs. & 7.07 & 20.6 & 57 & $3 \cdot 32$ & 6.4 & 34.25 & 47 & $3 \mathrm{I} . \mathrm{I}$ & 60.2 \\
\hline $\begin{array}{l}\text { Total } \\
\text { Per Cent Whole Staff }\end{array}$ & 153.75 & 96.8 & 201.25 & 48.4 & 27.6 & 113.25 & 31.5 & 28.5 & 56.3 \\
\hline
\end{tabular}

* Includes photo tat at Harvard.

1944 figures for Harvard and Texas; 1943 figures for Illinois.

\section{College Libraries in 1840}

College librarians associated with administrators and appropriating bodies who lack library consciousness may be interested in reading a forceful statement on this subject written in 1840 by William Capers. In lamenting the meagerness of a book collection of a college belonging to his denomination, this church paper editor and future bishop stated:

This positively will not do. . . A college with a library of "six hundred volumes!" Why it is a libel on a college library.... Better build cabins for recitation rooms, and cabins for dormitories, and a good large log cabin for a well-chosen library of 5000 volumes worth $\$ 15,000$ to $\$ 20,000$, and another for philosophical apparatus worth $\$ 10,000$, and another inclosing a tower of brick for an observatory, better this for a college, than the most splendid edifice of brick or stone, without books. ${ }^{1}$
C. H. Quenzel, Librarian E. Lee Trinkle Library Mary Washington College of the University of Virginia Fredericksburg

1 Godbold, Albea. The Church College of the Old South. Durham, N.C., Duke University Press, 1944, p.80. This quotation is used with the gracious permission of the Duke University Press. 